Transition to a more even distribution of daily protein intake is associated with enhanced fat loss during a hypocaloric \& physical activity intervention in obese older adults

by

\title{
Samaneh Farsijani
}

BSc, Shahid Beheshti University of Medical Sciences, 2007

MSc, King's College, University of London, 2010

PhD, McGill University, 2017

\author{
Submitted to the Graduate Faculty of the \\ Department of Epidemiology \\ Graduate School of Public Health in partial fulfillment \\ of the requirements for the degree of \\ Master of Science
}

University of Pittsburgh 


\section{UNIVERSITY OF PITTSBURGH}

\section{GRADUATE SCHOOL OF PUBLIC HEALTH}

This thesis was presented

by

\section{Samaneh Farsijani}

It was defended on

December 8, 2020

and approved by

Anne B. Newman, MD, MPH, Chair, Department of Epidemiology

Subashan Perera, PhD, Professor, Department of Medicine

Robert M. Boudreau, PhD, Assistant Professor, Department of Epidemiology

Thesis Advisor/Dissertation Director

Anne B. Newman, MD, MPH, Chair, Department of Epidemiology 
Copyright (C) by Samaneh Farsijani 


\title{
Transition to a more even distribution of daily protein intake is associated with enhanced fat loss during a hypocaloric \& physical activity intervention in obese older adults
}

\author{
Samaneh Farsijani, MS
}

University of Pittsburgh, 2020

\begin{abstract}
Background: Optimization of intentional weight loss in obese older adults, through preferential fat mass reduction, is challenging, as the concomitant lean mass loss may exacerbate sarcopenia. Recent studies have suggested within-day distribution of protein intake plays a role in determining body composition remodeling. Here, we assessed whether changes in within-day protein intake distribution are related to improvements in body composition in overweight/obese older adults during a hypocaloric and exercise intervention.

Methods: Thirty-six community-dwelling, overweight-to-obese (BMI 28.0-39.9 kg/m²), sedentary older adults (aged 70.6 \pm 6.1 years) were randomized into either physical activity plus successful aging health education $(\mathrm{PA}+\mathrm{SA} ; \mathrm{n}=15)$ or physical activity plus weight loss (PA+WL; $\mathrm{n}=21$ ) programs. Body composition (by CT and DXA) and dietary intake (by three-day food records) were determined at baseline, 6-month, and 12-month follow-up visits. Within-day protein distribution was calculated as the coefficient of variation $(\mathrm{CV})$ of protein ingested per defined time periods (breakfast [5:00-10:59], lunch [11:00-16:59] and dinner [17:00-1:00]). Secondary analysis was performed to determine associations between changes in protein intake distribution and body composition.
\end{abstract}

Results: In both groups, baseline protein intake was skewed towards dinner (PA+SA: 49.1\%; PA+WL: 54.1\%). The pattern of protein intake changed towards a more even within-day distribution in $\mathrm{PA}+\mathrm{WL}$ during the intervention period, but it remained unchanged in PA+SA. 
Transition towards a more even pattern of protein intake was independently associated with a greater decline in BMI $(P<0.05)$ and abdominal subcutaneous fat $(P<0.05)$ in PA+WL. However, changes in protein $\mathrm{CV}$ were not associated with changes in body weight in PA+SA.

Conclusion: Our results show that mealtime distribution of protein intake throughout the day was associated with improved weight and fat loss under hypocaloric diet combined with physical activity. Given that obesity is a major public health concern, our finding provides a novel insight into the potential role of within-day protein intake on weight management especially in obese older adults. 


\section{Table of Contents}

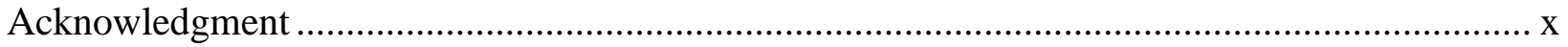

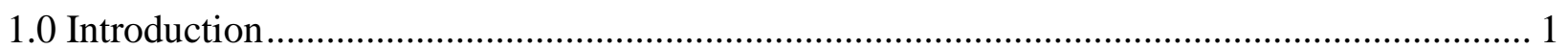

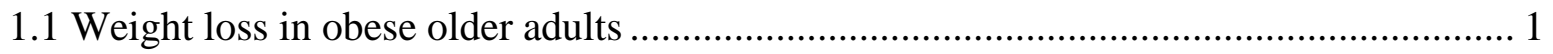

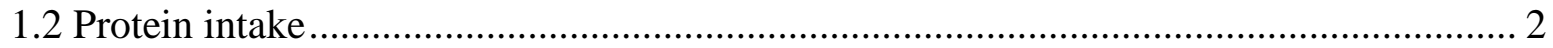

1.2.1 Protein intake and aging outcomes ......................................................

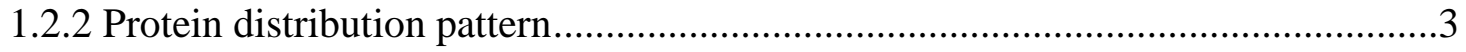

1.2.2.1 Within-day distribution of protein intake and muscle health in aging ...... 3

1.2.2.2 Patterns of protein intake and weight loss ...................................... 4

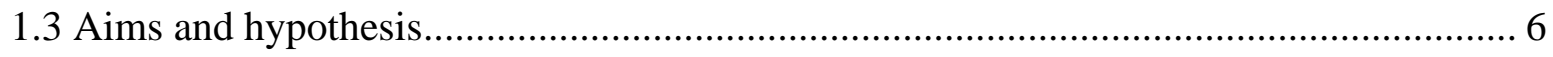

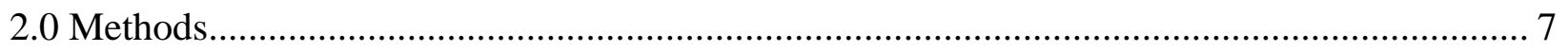

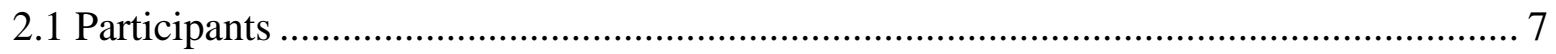

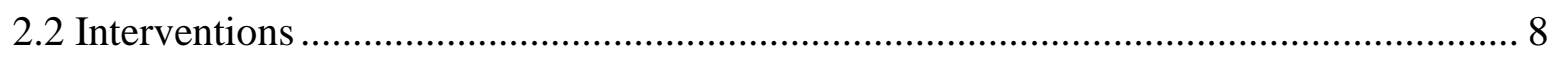

2.2.1 Physical Activity Program ................................................................

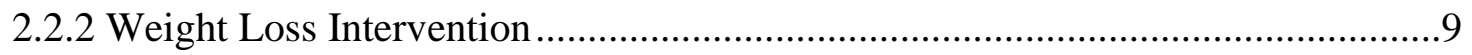

2.2.3 Successful Aging (SA) Health Education Intervention .................................10

2.3 Outcome measurements............................................................................. 10

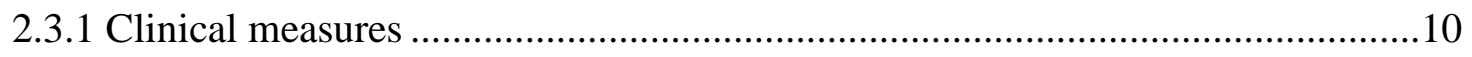

2.3.2 Dual Energy X-ray Absorptiometry (DXA) ............................................11

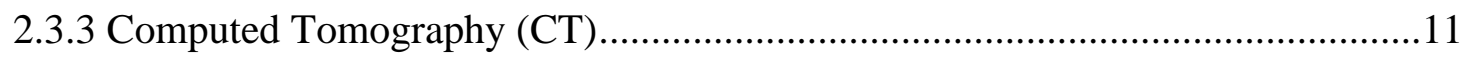

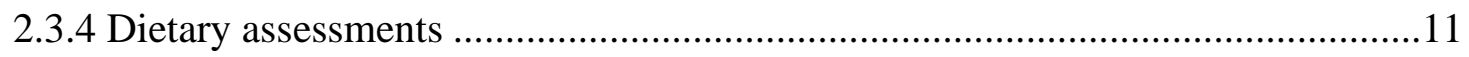

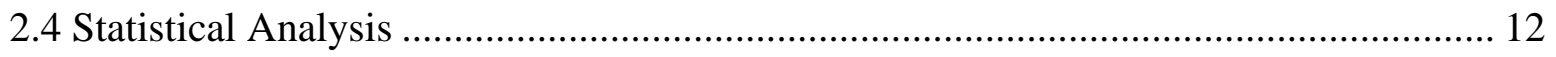




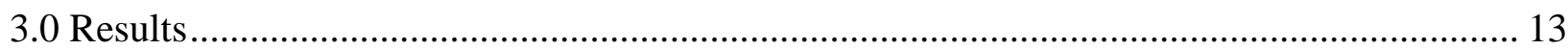

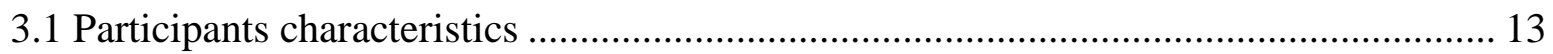

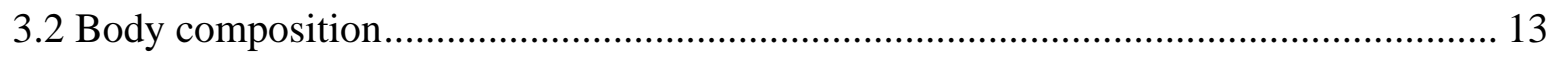

3.2.1 Anthropometrics and DXA ………………..............................................13

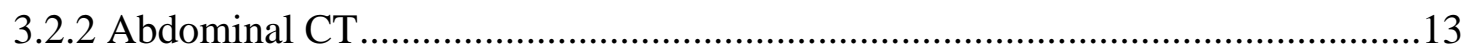

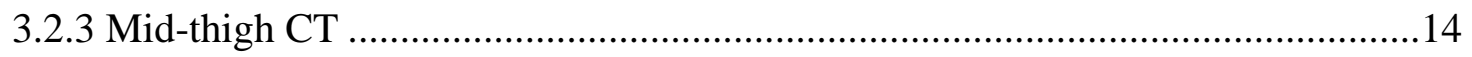

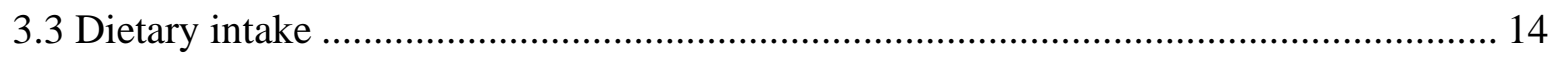

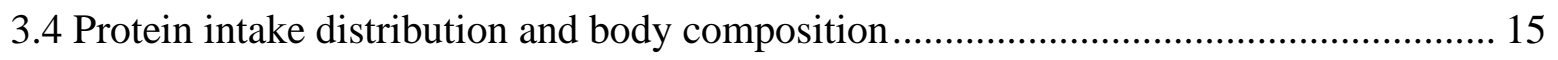

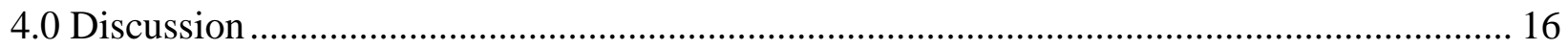

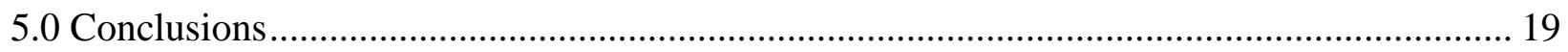

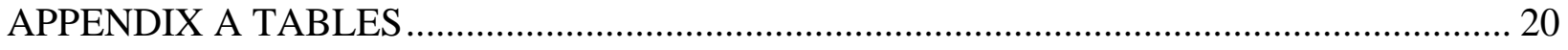

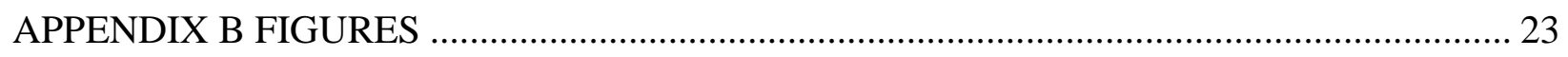

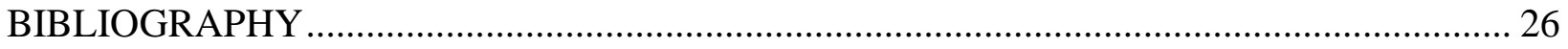




\section{List of Tables}

Table 1. Baseline and 1-y changes in body composition and nutrient intake by intervention

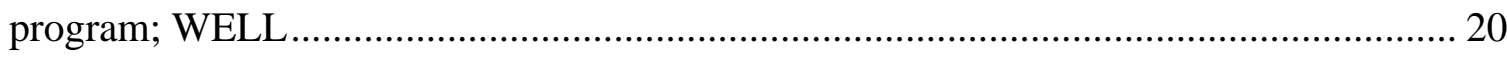

Table 2. Association between 1-y change $(\Delta)$ in within-day protein intake distribution and body composition by intervention program....... 


\section{List of Figures}

Figure 1. Mean \pm SD of baseline protein intake per meal and per day by intervention program. 23

Figure 2. Mean \pm SE of baseline and 1-y change of protein intake distribution ....................... 24

Figure 3. Relationship between 1-y changes in protein intake distribution and BMI by intervention

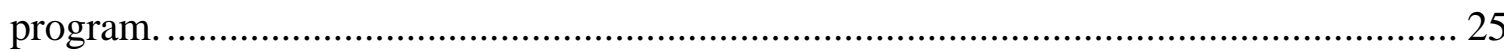




\section{Acknowledgment}

First and foremost, I would like to thank my mentor Dr. Anne Newman for her endless support and trust in me throughout my Post-doctoral and Master's trainings. I would like to extend my gratitude to Dr. Subashan Perera and Dr. Robert Boudreau for serving as my committee members. I would also like to thank my co-authors of the paper which was published based on the work presented in this thesis: Dr. Jane Cauley, Dr. Adam Santanasto, and Dr. Nancy Glynn. Also, my sincere thanks to Dr. Glynn, the Director of Master's Degree Program, who generously helped me throughout my training in this program. This work was supported by a Center for Disease Control cooperative agreement (1 U48 DP000025). ClinicalTrials.gov identifier: NCT00714506 and Epidemiology of Aging training grant at the University of Pittsburgh (NIA T32-AG0001810). 


\subsection{Introduction}

\subsection{Weight loss in obese older adults}

Obesity, i.e., body mass index (BMI) over $\geq 30 \mathrm{~kg} / \mathrm{m}^{2}$, is a common health issue in older adults, affecting $35 \%$ of people aged $\geq 60$ years $[1,2]$. Numerus health problems are associated with obesity in older adults including diabetes, cancer and osteoarthritis [3]. Obesity related complications are a major source of health care service use and lead to an increased rate of mortality and morbidity [4]. Additionally, obesity is associated with reduced physical function (e.g., muscle strength and walking speed) and muscle quality, which may arise from increased muscle lipid content [5, 6], leading to mobility disability [7], falls and fractures [8, 9].

An ideal weight loss strategy is designed to yield optimal changes in body composition by reducing excess fat mass, while preserving muscle mass. Studies have shown that a significant component of diet-induced weight loss is attributable to the loss of fat-free mass, which may reach to $\sim 20-30 \%$ [10]. Weight loss interventions that preferentially decrease fat mass are particularly challenging in older persons, as the concomitant muscle mass loss may exacerbate sarcopenia. Of note, increasing the fat-to-muscle loss ratio during weight management is more complicated in older people [11] due to their lower physical activity and coexisting chronic diseases.

Calorie restriction is a major catabolic stimulus and the mainstay of dietary interventions in weight reduction and leads to the loss of both fat and lean mass [12-14]. Several studies have shown that weight loss through energy restriction leads to muscle protein synthesis rate both in 
fast and fed state, which ultimately results in muscle mass loss [15, 16]. Growing evidence suggests that exercise and increased dietary protein intake have been suggested as the two main strategies to maintain muscle mass during weight loss $[17,18]$.

\subsection{Protein intake}

\subsubsection{Protein intake and aging outcomes}

Recommended dietary allowance (RDA) for protein $(0.8 \mathrm{~g}$ per $\mathrm{kg}$ of the body weight per day) is primarily based on the amount of proteins required to maintain nitrogen balance over a short period of time and is largely driven by studies performed in young adults [19, 20]. However, growing evidence suggests that the current RDA may not be adequate to maintain or promote muscle health in older people, who are already experiencing muscle mass and physical function declines [21, 22]. Moreover, 31-50\% of US older adults older (above 50 years of age) do not meet the RDA for protein [23]. The anabolic stimulating properties of the dietary proteins and their amino acid contents has been proposed to promote or maintain muscle protein synthesis in older adults [24]. Additionally, epidemiological studies have than increased dietary protein intake is associated with higher muscle mass and better physical performance in community dwelling old men and women from the Quebec Longitudinal Study on Nutrition and Aging (NuAge). Consistently, higher dietary protein intake has been shown to be associated with a reduced 3-year decline in lean body mass in community-dwelling older adults participating in the Health, Aging, and Body Composition (Health ABC) cohort [25]. Therefore, in response to recent evidence supporting the role of increased protein intake in overcoming the age-decline in muscle mass and 
function, the PROT-AGE expert group has recommended a higher amount of protein intake (1.0$1.2 \mathrm{~g} / \mathrm{kg}$ body weight per day) than the current RDA for protein in community older adults [26]. In addition to these observational studies performed in the community setting and on people following ad lib diet, studies have shown that increasing total protein intake $(1.2-1.5 \mathrm{~g} / \mathrm{kg}$ body weight/d) may preserve muscle mass and reduce fat mass during weight loss in obese individuals following a hypocaloric diet [27, 28].

\subsubsection{Protein distribution pattern}

\subsubsection{Within-day distribution of protein intake and muscle health in aging}

In addition to the daily amount of protein intake, within-day distribution patterns of protein intake has been suggested to be an important modifier of muscle protein synthesis, muscle mass and function [21, 29, 30]. According to the National Health and Nutrition Examination Survey (NHANES, from data collected in 2001-2008), within-day patterns of daily protein intake among US adults (aged $\geq 19$ years) is skewed, with breakfast minimally contributing to total protein intake, while highest amount of protein is consumed at supper [31]. However, it has been suggested that ingesting equal amount of proteins at each meal, irrespective of the amount of protein intake, may promote muscle mass and function compared to a skewed pattern of intake [32].

The importance of equal distribution of protein intake throughout the day ( 30g per meal) stems from a main concept that a threshold of high quality protein must be reached at each meal to maximally stimulate muscle protein synthesis [33, 34], particularly in older people who are experiencing blunted muscle protein anabolism [35]. However, the majority of the studies 
addressing protein intake distribution and body composition were conducted during an energybalanced diet/ usual calorie intake or under a hypocaloric diet in young obese adults over a short period of time [30]. Paddon-Jones et al. [29], in a 7-day cross-over study on 8 young adults (37 \pm 3 years) showed that even within-day distribution of protein intake (i.e., ingesting 31.5 $\pm 1.3,29.9$ \pm 1.6 , and $32.7 \pm 1.6 \mathrm{~g}$ protein at breakfast, lunch, and dinner, respectively) was associated with higher 24-h muscle protein synthesis compared to a skewed pattern of intake $(10.7 \pm 0.8,16.0 \pm$ 0.5 , and $63.4 \pm 3.7 \mathrm{~g}$ protein, respectively). Although, short-term clinical trials have shown the beneficial effect of even patterns of protein intake in stimulating 24-h muscle protein synthesis, the current evidence is limited to support these beneficial effects can ultimately translate into preserving muscle mass and function in older adults in long-term. In a large longitudinal cohort study, we showed that a more evenly distributed pattern of protein intake within-day is associated with higher lean mass [21] and muscle strength [22] in community-dwelling older men and women. In response to the emerging evidence, intake of 0.4-0.6 g protein per $\mathrm{kg}$ of body weight has been recommended to exert beneficial effects on muscle health and reduce age-associated muscle loss in aging [36]. This recommendation also results in a daily intake of $1.2-1.8 \mathrm{~g}$ protein per kg of body weight, which is higher than the current RDA and the increased intake level recommended by the PROT-AGE expert group.

\subsubsection{Patterns of protein intake and weight loss}

The effect of within-day distribution of protein intake on body composition in obese older adults undergoing intentional weight loss is unclear. To our knowledge, only few studies have examined the effect of within-day pattern of protein intake under energy restriction diet on muscle synthesis in obese individuals. Murphy et al. (2015) in a 4-week randomized clinical trial showed 
that an even pattern of protein intake (i.e., $25 \%$ daily protein/meal $\times 4$ ) acutely simulated shortterm (11 hours) muscle protein synthesis in overweight/obese older men $(66 \pm 4$ years; $\mathrm{N}=30)$ compared to a skewed intake (7:17:72:4\% daily protein/meal) [15]. Further, they showed that even pattern of protein intake was more beneficial in preserving myofibrillar protein synthesis when combined with resistance training. However, participants were fed with isolated proteins during the infusion trial (using $13-\mathrm{h}$ primed continuous infusion of L- $\left[\right.$ ring- $\left.{ }^{13} \mathrm{C}_{6}\right]$ phenylalanine techniques) to measure muscle protein synthesis response in Murphy's study. Therefore, the observed effect may not fully disclose the effect of even vs. skewed protein intake diet that participants were fed before the short-term protein synthesis assay.

To determine the longer term effect of daily protein distribution on muscle synthesis, the same group [37] provided oral deuterated water $\left(\mathrm{D}_{2} \mathrm{O}\right)$ to obese men under hypocaloric diet and measured synthesis of the myofibrillar protein sub-fraction (bulk MyoPS) and the synthesis rates of individual skeletal muscle proteins over two weeks using tandem-mass spectrometric proteomic analyses. In contrast to their previous findings, even pattern of protein intake, with and without exercise training, failed to stimulate the bulk MyoPS and synthesis rates of individual skeletal muscle proteins during energy restriction [37]. Understanding the influence of daily patterns of protein intake on maintaining muscle synthesis and ultimately preserving muscle mass, while enhancing fat mass loss, in obese older adults during weight loss can help to design dietary strategies for obese individuals to promote a healthy body composition. It has been anticipated that the intake of average $\sim 40-48 \mathrm{~g}$ protein per meal in obese older adults under hypocaloric diet may exert beneficial effects on muscle health through promoting muscle protein synthesis [15]. However, further studies are required to validate this recommendation. 


\subsection{Aims and hypothesis}

To determine the association between changes in mealtime dietary protein intake and improvements in body composition under a hypocaloric diet, we performed a secondary analysis of our previous long-term randomized controlled trial of Wellness for Elders through Lifestyle and Learning (WELL) [38, 39]. In this trial, 36 overweight/obese older adults underwent 12 months of calorie restriction and exercise intervention $v s$. exercise alone with intensive dietary and body composition assessment. We hypothesize that changing the pattern of protein intake to a more even distribution within the day, independent of the protein quantity, is associated with greater weight loss during a one-year caloric restriction and physical activity intervention in over weight/obese older men and women. 


\subsection{Methods}

\subsection{Participants}

A total of 36 older individuals (age $70.6 \pm 6.1$ years) were enrolled in a one-year pilot randomized controlled trial called the Wellness for Elders through Lifestyle and Learning (WELL) study. Participant recruitment and screening have been described in detail elsewhere [38, 39]. In brief, community-dwelling older ( $\geq 60$ years) and overweight to obese (BMI between 28.0 and $39.9 \mathrm{~kg} / \mathrm{m}^{2}$ ) men and women with a sedentary lifestyle (formal exercise $<3$ times per week for a total time of $<90 \mathrm{~min} /$ week) from the greater McKeesport, PA area were invited by mail. Those who were interested ( $\mathrm{n}=193)$ were telephone screened for the assessment of initial eligibility followed by two screening visits. Inclusion criteria were: 1) self-reported ability to walk $1 / 4$ mile (2-3 blocks); 2) ability to walk $400 \mathrm{~m}$ in $<15$ minutes without the use of an assistive device; 3 ) the ability and willingness to complete an activity $\log$ and food diary and to attend meetings and physical activity sessions in McKeesport, PA; and 4) the willingness to be randomized to either intervention program. Exclusion criteria consisted of: 1) severe medical conditions preventing participation in a diet and/or exercise intervention; 2) cognitive impairment (Modified MiniMental State Exam score $<80$ or diagnosis of dementia); 3) inappropriate age or BMI; 4) weight loss of $>4.5 \mathrm{~kg}$ in the past four months; and 4) consumption of medications for obesity.

Eligible participants were randomized into either the Physical Activity plus Weight Loss $(\mathrm{PA}+\mathrm{WL}, \mathrm{n}=21)$ or Physical Activity plus Successful Aging Health Education $(\mathrm{PA}+\mathrm{SA}, \mathrm{n}=15)$ group. Randomization was performed by using a Microsoft Access-based random-number 
generating algorithm with stratification by age and sex. All of the participants provided written informed consent, and the research protocol was approved by the University of Pittsburgh Institutional Review Board.

\subsection{Interventions}

\subsubsection{Physical Activity Program}

All participants, regardless of their group assignment, received the physical activity intervention (PA). The PA program was divided into three phases; adoption (weeks 1-8), transition (weeks 9-24), and maintenance (weeks 25-52). The aim of this three-phase program was to facilitate a gradual transition of the exercise training from the clinic setting into the participants' daily routine.

During the adoption phase, participants were required to attend 3 center-based exercise sessions per week. Each session was $\sim 60$ minutes and mainly focused on treadmill walking followed by lower extremity resistance training, balance exercises and stretching. The goal was to increase treadmill walking to at least $150 \mathrm{~min} /$ week by week 9 . During the transition phase, centerbased exercise sessions were reduced to 2 sessions per week supplemented with one or more homebased sessions. During the maintenance phase, participants were expected to perform exercise at least 3 times per week at home. They also had the option to participate in one center-based exercise session per week. 


\subsubsection{Weight Loss Intervention}

The goal was to achieve $7 \%$ weight loss by 6 months and to maintain it for the remainder of the trial in participants in the PA+WL arm. Participants were assigned to one of the following daily goals as recommended by the Diabetes Prevention Program: 1,200 kcal/day (33 $\mathrm{g}$ fat) for participants with an initial weight of 120-170 lbs, 1,500 kcal/day (42 $\mathrm{g}$ fat) for participants with a weight of 175-215 lbs, 1,800 kcal/day (50 g fat) for participants with a weight of 220-245 lbs, and 2,000 kcal/day (55 g fat) for participants weighing >250 lbs [40]. Participants were advised to reduce dietary fat to $\sim 25 \%$ of total energy intake, consume mono- and poly- unsaturated fat instead of saturated fat and cholesterol, and include at least 5 servings of fruits and vegetables and 6 servings of grains, especially whole grains, in their daily diet. Of note, no recommendations were provided to the participants about the within-day distribution of dietary protein intake in the original RCT.

Participants received 24 weekly, 2 bi-monthly, and 5 monthly sessions led by a nutritionist. Participants were asked to keep food records for at least 6 days per week during the first 6 months and monthly thereafter. Participants were weighed at each session; their performance was evaluated and strategies to achieve the recommended calorie intake were discussed. If a participant had difficulty adhering to the WL intervention, the study nutritionist scheduled a one-on-one session with the participant. The overall adherence to this arm of the intervention was assessed by determining the percentage of the participants who met the weight loss goal. 


\subsubsection{Successful Aging (SA) Health Education Intervention}

Participants randomized into PA+SA attended successful aging health education workshop series once a month (12 sessions in total each lasted 60-minutes). The workshops were based on "The Ten Keys to Healthy AgingTM" [41] and the SA program developed for Lifestyle Interventions and Independence for Elders-Pilot Study [42].

\subsection{Outcome measurements}

The following clinical and body composition data were recorded at baseline and two follow-up visits at 6 and 12 months after the enrollment.

\subsubsection{Clinical measures}

Body weight $(\mathrm{kg})$ and height $(\mathrm{cm})$ were measured to calculate BMI $\left(\mathrm{kg} / \mathrm{m}^{2}\right)$. Participants also completed questionnaires on sociodemographic and medical history. Physical activity (minutes/week) was quantified by the Community Healthy Activities Model Program for Seniors (CHAMPS) physical activity questionnaire [43]. The CHAMPS questionnaire was also used to assess adherence to the PA intervention. 


\subsubsection{Dual Energy X-ray Absorptiometry (DXA)}

Total body lean mass (excluding bone) and fat mass were assessed by DXA (Hologic QDR 4500, software version 12.3; Bedford, MA) [44]. Appendicular lean mass (aLM) was calculated as the sum of upper and lower extremity lean masses.

\subsubsection{Computed Tomography (CT)}

Axial CT scans (9800 Advantage, General Electric, Milwaukee, WI) were used to quantify cross-sectional areas (CSA) of total, visceral and subcutaneous abdominal fat as well as CSA of mid-thigh muscle, intramuscular fat and muscle density (Hounsfield Unit, HU), using established methods $[38,45,46]$.

\subsubsection{Dietary assessments}

Dietary intake was assessed by three-day food records at baseline, 6-month and 12-month follow-ups. At the beginning of the study, participants were instructed on how to report the intake of all foods and beverages using household measures or a scale as well as the time of intake. Food records were analyzed by Nutrition Data System for Research (NDSR) software developed at the Nutrition Coordinating Center of the University of Minnesota's School of Public Health.

Total protein intake was calculated by the nutrient residual energy-adjusted method [21]. Absolute protein intake was regressed on total energy intake to compute residuals to remove the effect of total energy intake on protein intake. To assess mealtime distribution of protein intake, 
we categorized protein consumption based on the time of intake into; breakfast (5:00 - 10:59), lunch $(11: 00-16: 59)$ and dinner (17:00 - 1:00). Additionally, the evenness of protein intake distribution across the three meals was calculated for each participant using the coefficient of variation $(\mathrm{CV})$, as $\mathrm{CV}=\mathrm{SD}$ of protein intake $(\mathrm{g} / \mathrm{meal}) /$ mean protein intake $(\mathrm{g} / \mathrm{d})[21]$. The mean $\mathrm{CV}$ averaged over the 3 days was then calculated. Lower protein $\mathrm{CV}$ values reflect the evenness of within-day protein intake. Participants' diet remained stable during the two follow up visits at 6 and 12 months compared to the baseline intake. Therefore, we pooled the food records obtained at 6 and 12 months, as the participants' representative diet during the one-year follow up.

\subsection{Statistical Analysis}

Participants' characteristics are shown as means \pm SDs for continuous variables and as percentages for categorical variables by intervention groups. Baseline and 1-y changes (i.e., 12months - baseline) were compared within and between PA+SA and PA+WL groups using parametric (i.e., paired-sample t-test and independent sample t-test) and nonparametric (i.e., Wilcoxon and Mann-Whitney U test) tests. General linear model, Univariate ANOVA, was used to test the association between changes in protein $\mathrm{CV}$ and body composition by intervention group, controlled for their baseline values, total calorie and protein intake. Statistical analyses were performed with SPSS Version 24 (IBM SPSS Statistics, Chicago, IL, USA). 


\subsection{Results}

\subsection{Participants characteristics}

A total of 36 participants were included in this study ( $\mathrm{n}=21$ in the PA+WL group; $\mathrm{n}=15$ in the PA+SA group). Baseline age was $71.0 \pm 5.8$ years. The majority of participants were women (83\%) and Caucasian (83\%).

\subsection{Body composition}

\subsubsection{Anthropometrics and DXA}

Body weight, BMI, fat mass and aLM were comparable between the intervention groups at baseline (Table 1). After one year, participants in PA+WL experienced a significant decline in weight (5.4\%) and BMI (5.1\%) compared to those in PA+SA (1\% and $0.7 \%$, respectively), $P<$ 0.05 (Table 1). We also observed significant declines in the whole body fat mass $(9 \%, P<0.001)$ and aLM $(4.5 \%, P<0.01)$ within the PA+WL group; and trends towards reductions in the PA+SA group $\operatorname{arm}(3.3 \%, P=0.06$ and $1.6 \%, P=0.08$, respectively).

\subsubsection{Abdominal CT}

Total abdominal fat was higher in the $\mathrm{PA}+\mathrm{WL}$ group compared to $\mathrm{PA}+\mathrm{SA}$ at baseline, $P=$ 0.04 (Table 1). There was a significant reduction in total $(12.3 \%, P<0.01)$, visceral $(16 \%, P<$ 
$0.01)$ and subcutaneous $(10.5 \%, P<0.05)$ abdominal fat within the PA+WL arm of the study after one year; but not in the PA+SA group, Table 1.

\subsubsection{Mid-thigh CT}

Intramuscular fat, muscle density and muscle area were comparable between the programs at baseline (Table 1). Intramuscular fat significantly declined in both PA+WL $(25.6 \%, P<0.001)$ and PA+SA $(13.6 \%, P<0.05)$ groups. However, the 12-month decrease in the quadriceps muscle area was only significant in the PA+WL group $(5.5 \%, P<0.01)$.

\subsection{Dietary intake}

Total energy and macronutrients (fat, carbohydrates and protein) intakes were similar at baseline between the intervention groups. Participants in the PA+WL group reduced their total calorie intake by $4.3 \%(P=0.012)$ and fat intake by $3.3 \%(P=0.042)$ during the 1 -year follow-up. However, nutrient intakes remained unchanged in the PA+SA group, Table 1.

In both groups, baseline protein intake was comparably skewed towards dinner $(49.1 \%$ for $\mathrm{PA}+\mathrm{SA}$ and $54.1 \%$ for PA+WL) (Figure 1). Breakfast (16.3\% in PA+SA and $19.3 \%$ in PA+WL group) and lunch $(34.6 \%$ in $\mathrm{PA}+\mathrm{SA}$ and $26.5 \%$ in $\mathrm{PA}+\mathrm{WL})$ had smaller contribution to the total

protein intake. However, the pattern of protein intake changed towards a more even within-day distribution in participants in the PA+WL arm during the intervention (protein intake $\mathrm{CV}$ of 0.81 
\pm 0.22 at baseline vs. $0.70 \pm 0.19$ during the follow ups, $P<0.05$ ) (Figure 2). Within-day distribution of protein intake remained unchanged in the PA+SA group during the follow ups.

\subsection{Protein intake distribution and body composition}

Table 2 shows the associations between changes in protein intake distribution and changes in BMI, weight, subcutaneous abdominal fat and quadriceps muscle cross-sectional area, after controlling for their baseline values, total calorie and protein intake. For participants in the $\mathrm{PA}+\mathrm{WL}$ group, the transition towards a more even distribution of protein intake throughout the day (i.e., decrease in protein intake CV) was independently associated with a greater decline in BMI $(P<0.05)$ and abdominal subcutaneous fat $(P<0.05)$ (Figure 3 and Table 2$)$. Similarly, the decline in protein $\mathrm{CV}$ was associated with a trend toward higher weight loss after one year in the PA+WL group $(P=0.06)$. However, changes in protein $\mathrm{CV}$ were not associated with changes in BMI, abdominal subcutaneous fat or weight in participants in the PA+SA group. Moreover, changes in within-day distribution of protein were not related to changes in mid-thigh quadriceps muscle cross-sectional area (Table 2), whole body fat mass, lean mass, abdominal visceral fat and mid-thigh intramuscular fat (data not shown) in either group. Of note, neither total calorie intake nor total protein intake was significantly related to body composition changes (Table 2). 


\subsection{Discussion}

The results of this study demonstrate that a transition towards a more even distribution of protein intake throughout the day (i.e., decrease in protein intake CV value) under a hypocaloric dietary and physical activity intervention was independently associated with a greater decline in weight, BMI and abdominal subcutaneous fat.

In a nationally representative sample of U.S. adults from the 1999-2002 NHANES data ( $n=1,081$ people; age $50-85$ years), it has been shown that the majority of daily protein intake is consumed during the evening meal (44\%) [47]. In agreement with this observation, within-day pattern of protein intake among our study participants was skewed towards dinner, while breakfast minimally contributed to total daily protein intake.

Over the past several years, there has been a growing attention to the role of distribution of daily protein intake, in addition to its quantity, as a strategy to maximally stimulate muscle protein synthesis [33, 34]. A meal-driven approach of protein intake throughout the day may be particularly important in senior adults who are experiencing a blunted muscle protein anabolism, i.e., anabolic resistance of aging [35]. It has been shown that higher doses of essential amino acids (10-15 g/meal) compared to low doses $(\sim 7.5 \mathrm{~g} / \mathrm{meal})$ are required to stimulate muscle protein anabolism in older individuals to a similar extent as in younger adults [26, 29]. However, one potential limitation is that the acute changes in muscle protein synthesis may not translate into enduring changes in body composition over long periods of time [48]. A few longitudinal studies have also suggested potentially beneficial effects of equal distribution of protein intake on body 
composition in older adults [21]. However, the majority of these studies were performed on subjects who consumed a balanced-calorie diet with only a few studies addressing the associations between distribution of protein intake and body composition parameters during a hypocaloric weight-loss regimen [30].

In the present study, we extended the scope of the previous investigations by exploring the potential association between within-day distribution of protein intake and adipose tissue loss. We noted a shift in within-day distribution of protein intake in the intervention group (PA+WL); where protein intake was re-distributed from dinner to other meals, particularly lunch (has not been shown in results). Moreover, shifting to a more even pattern of protein intake was independently associated with greater weight and subcutaneous abdominal fat mass losses in participants in the $\mathrm{PA}+\mathrm{WL}$ group. One possible mechanism linking more even protein intake to weight loss is the satiation effect of protein ingestion, leading to reduction in food intake. Also, increased thermogenesis associated with protein consumption may contribute to weight loss by increasing the energy expenditure [49]. However, our finding is in contrast to a recent short-term (16 week) clinical trial in which within-day distribution of protein intake had no significant effect on fat mass reduction in young overweight adults on an energy-restricted and resistance training program [30]. The differences in the study population (older vs. younger adults) and the study period (12 month vs. 16 week) may contribute to the inconsistencies in our results.

To address the relationship between the intake of other nutrients and weight loss, in our study, the association between protein intake distribution and weight loss was assessed after adjustment for total calorie and protein intake. Of note, neither total daily energy intake nor protein 
intake were related to the observed weight changes in our study. One possibility for the lack of association between other dietary factors and body composition is that the magnitude of changes in calorie and macro-nutrient intake was not sufficiently different from baseline to detect measurable effects on body composition. Additionally, the observed independent association between even protein intake within-day and weight loss may be related to the circadian timing of protein intake. It has been shown that skewed consumption of foods towards dinner (i.e., during the circadian evening or night) is associated with increased body fat independent of total calorie or nutrient contents [50].

A strength of the current study was the collection of dietary data through food records that reduces the potential recall bias that is observed with $24-\mathrm{h}$ food recalls or food frequency questionnaires. Dietary data collection through food recall also allowed us to accurately determine the within-day distribution of protein intake. Additionally, the quantification of within-day protein intake distribution by calculating protein $\mathrm{CV}$ as a continuous variable, as opposed to categories with arbitrary cut offs, makes our statistical approach more robust and generalizable to populations with various patterns of protein intake.

This study has a few limitations to consider. First, there was a small number of participants, as this was a pilot clinical trial. Also, study participants were mostly Caucasians and female, which limits the generalizability of our data to other races or men. Additionally, the absence of a WL and SA intervention group limits us to discriminate the effect of protein intake distribution on weight loss under hypocaloric diet alone from the physical activity. 


\subsection{Conclusions}

In summary, our results show that mealtime distribution of protein intake throughout the day was associated with improved weight and fat mass loss under hypocaloric diet combined with exercise. This finding may have implications in the optimization of weight management interventions in overweight/obese older people by allowing for a preferential loss of fat mass. 


\section{APPENDIX A TABLES}

Table 1. Baseline and 1-y changes in body composition and nutrient intake by intervention

\section{program; WELL}

\begin{tabular}{|c|c|c|c|c|c|}
\hline & \multicolumn{2}{|l|}{$\mathbf{P A}+\mathrm{WL}$} & \multicolumn{2}{|c|}{$\mathbf{P A}+\mathbf{S A}$} & \multirow[b]{2}{*}{$P_{\text {between }}$} \\
\hline & $\mathrm{N}=21$ & $P_{\text {within }}$ & $\mathrm{N}=15$ & $P_{\text {within }}$ & \\
\hline Age, y & $71.29 \pm 5.90$ & & $70.53 \pm 5.94$ & & 0.71 \\
\hline Women, n (\%) & $17(81 \%)$ & & $13(86.7)$ & & 0.65 \\
\hline Caucasian, n (\%) & $19(90.5)$ & & $11(73.3)$ & & 0.17 \\
\hline Physical activity, min/wk & $716.43 \pm 451.20$ & & $1025.00 \pm 595.82$ & & $0.10^{2}$ \\
\hline$\Delta \mathrm{BL}-12 \mathrm{~m}$ & $217.14 \pm 576.51$ & $0.12^{1}$ & $116.00 \pm 450.87$ & $0.27^{1}$ & 0.58 \\
\hline \multicolumn{6}{|l|}{ Bodv composition } \\
\hline Weight, kg & $89.76 \pm 10.04$ & & $85.38 \pm 6.52$ & & 0.15 \\
\hline$\Delta \mathrm{BL}-12 \mathrm{~m}$ & $-4.86 \pm 6.11$ & 0.004 & $-0.83 \pm 3.00$ & 0.32 & 0.031 \\
\hline BMI, $\mathrm{kg} / \mathrm{m}^{2}$ & $33.36 \pm 3.28$ & & $32.15 \pm 3.05$ & & $0.29^{2}$ \\
\hline$\Delta \mathrm{BL}-12 \mathrm{~m}$ & $-1.70 \pm 2.27$ & $0.004^{1}$ & $-0.21 \pm 1.01$ & $0.68^{1}$ & 0.020 \\
\hline \multicolumn{6}{|l|}{ DXA } \\
\hline Fat mass, kg & $37.95 \pm 5.86$ & & $35.88 \pm 6.47$ & & 0.32 \\
\hline$\Delta \mathrm{BL}-12 \mathrm{~m}$ & $-3.43 \pm 3.21$ & 0.000 & $-1.20 \pm 2.19$ & 0.061 & 0.035 \\
\hline $\mathrm{aLM}, \mathrm{kg}$ & $20.59 \pm 3.72$ & & $19.70 \pm 2.84$ & & $0.47^{2}$ \\
\hline$\Delta \mathrm{BL}-12 \mathrm{~m}$ & $-0.92 \pm 1.28$ & 0.004 & $-0.31 \pm 0.64$ & $0.08^{1}$ & 0.13 \\
\hline \multicolumn{6}{|l|}{ CT Abdomen } \\
\hline Total Fat, $\mathrm{cm}^{2}$ & $661.46 \pm 134.14$ & & $569.57 \pm 97.58$ & & 0.036 \\
\hline$\Delta \mathrm{BL}-12 \mathrm{~m}$ & $-81.53 \pm 104.81$ & 0.005 & $-26.47 \pm 77.79$ & 0.24 & 0.12 \\
\hline Subcutaneous Fat, $\mathrm{cm}^{2}$ & $443.72 \pm 124.46$ & & $389.07 \pm 93.40$ & & $0.097^{2}$ \\
\hline$\Delta \mathrm{BL}-12 \mathrm{~m}$ & $-46.71 \pm 73.54$ & 0.019 & $-24.77 \pm 63.77$ & $0.31^{1}$ & 0.40 \\
\hline Visceral Fat & $217.75 \pm 61.26$ & & $179.80 \pm 47.89$ & & 0.062 \\
\hline$\Delta \mathrm{BL}-12 \mathrm{~m}$ & $-34.82 \pm 42.84$ & 0.004 & $-0.95 \pm 29.28$ & 0.91 & 0.021 \\
\hline CT mid-thigh & & & & & 0.001 \\
\hline Intramuscular fat, $\mathrm{cm}^{2}$ & $12.52 \pm 3.57$ & & $13.42 \pm 5.52$ & & 0.60 \\
\hline$\Delta \mathrm{BL}-12 \mathrm{~m}$ & $-3.20 \pm 2.22$ & 0.000 & $-1.83 \pm 2.64$ & 0.028 & 0.14 \\
\hline Muscle density, HU & $39.56 \pm 3.13$ & & $40.12 \pm 3.29$ & & $0.27^{2}$ \\
\hline$\Delta \mathrm{BL}-12 \mathrm{~m}$ & $0.66 \pm 1.54$ & 0.11 & $0.24 \pm 1.41$ & 0.55 & 0.46 \\
\hline Quadriceps Muscle, $\mathrm{cm}^{2}$ & $49.15 \pm 10.76$ & & $50.07 \pm 10.64$ & & $0.96^{2}$ \\
\hline$\Delta \mathrm{BL}-12 \mathrm{~m}$ & $-2.71 \pm 3.50$ & 0.007 & $-1.32 \pm 5.62$ & $0.25^{1}$ & $0.22^{2}$ \\
\hline \multicolumn{6}{|l|}{ Dietary intake } \\
\hline Energy, kcal & $1711.22 \pm 330.92$ & & $1729.99 \pm 339.11$ & & 0.87 \\
\hline$\Delta \mathrm{BL}-12 \mathrm{~m}$ & $-245.36 \pm 393.35$ & 0.012 & $-87.14 \pm 438.05$ & 0.49 & 0.29 \\
\hline Fat, \%kcal & $31.12 \pm 8.15$ & & $34.22 \pm 6.50$ & & 0.25 \\
\hline$\Delta \mathrm{BL}-12 \mathrm{~m}$ & $-3.32 \pm 6.82$ & 0.042 & $0.68 \pm 7.79$ & 0.76 & 0.13 \\
\hline Carbohydrate, $\% \mathrm{kcal}$ & $51.19 \pm 8.75$ & & $49.54 \pm 7.27$ & & 0.57 \\
\hline$\Delta \mathrm{BL}-12 \mathrm{~m}$ & $2.15 \pm 8.11$ & 0.25 & $-2.24 \pm 7.16$ & 0.28 & 0.12 \\
\hline Protein, \%kcal & $17.40 \pm 3.46$ & & $15.93 \pm 2.87$ & & 0.20 \\
\hline$\Delta \mathrm{BL}-12 \mathrm{~m}$ & $1.27 \pm 2.96$ & 0.07 & $1.28 \pm 3.84$ & 0.25 & 1.00 \\
\hline Protein, g/kg BW/d & $0.88 \pm 0.19$ & & $0.80 \pm 0.18$ & & 0.25 \\
\hline$\Delta \mathrm{BL}-12 \mathrm{~m}$ & $-0.07 \pm 0.22$ & 0.16 & $0.02 \pm 0.28$ & 0.76 & 0.27 \\
\hline Protein, energy adjusted g/d & $72.68 \pm 12.61$ & & $67.29 \pm 12.08$ & & 0.22 \\
\hline$\Delta \mathrm{BL}-12 \mathrm{~m}$ & $-2.31 \pm 12.03$ & 0.40 & $-1.10 \pm 16.34$ & 0.81 & 0.81 \\
\hline Protein distribution, $\mathrm{CV}$ & $0.81 \pm 0.22$ & & $0.70 \pm 0.20$ & & $0.14^{2}$ \\
\hline$\Delta \mathrm{BL}-12 \mathrm{~m}$ & $-0.13 \pm 0.23$ & 0.018 & $-0.02 \pm 0.29$ & 0.81 & $0.21^{2}$ \\
\hline
\end{tabular}


Values are means \pm SDs, unless otherwise indicated.

$\mathrm{P}_{\text {within }}$ values were derived by paired-sample t-test, unless otherwise indicated.

$P_{\text {between }}$ values were derived by independent sample $t$-test unless otherwise indicated.

1 derived by using Wilcoxon

2 derived by using independent sample Mann-Whitney $\mathrm{U}$ test

y, year; PA, Physical activity; WL, weight loss; SA, successful aging health education; BL, baseline; 12m, 12-month; HU, Hounsfield Unit; CSA, cross-sectional area; CV, coefficient of variation; BMI, Body Mass Index; DXA, dual x-ray absorptiometry; aLM, appendicular lean mass; CT, computed tomography. 
Table 2. Association between 1-y change $(\Delta)$ in within-day protein intake distribution and body composition by intervention program

\begin{tabular}{|c|c|c|c|c|}
\hline & \multicolumn{2}{|l|}{$\mathbf{P A}+\mathbf{W L}$} & \multicolumn{2}{|l|}{$\mathbf{P A}+\mathbf{S A}$} \\
\hline & $\beta \pm \mathrm{SE}$ & $\boldsymbol{P}$ & $\beta \pm \mathrm{SE}$ & $\boldsymbol{P}$ \\
\hline \multicolumn{5}{|l|}{ 1-y $\Delta$ BMI, kg/m² } \\
\hline 1-y $\Delta$ protein $\mathrm{CV}$ & $5.284 \pm 2.407$ & 0.047 & $-1.602 \pm 1.102$ & 0.18 \\
\hline $12 \mathrm{~m}$ Protein intake, $\mathrm{g} / \mathrm{d}$ & $0.029 \pm 0.041$ & 0.49 & $0.013 \pm 0.026$ & 0.64 \\
\hline $12 \mathrm{~m}$ Total energy intake, $\mathrm{kcal}$ & $0.002 \pm 0.002$ & 0.29 & $0.001 \pm 0.001$ & 0.26 \\
\hline BL BMI, $\mathrm{kg} / \mathrm{cm}^{2}$ & $0.079 \pm 0.163$ & 0.64 & $0.012 \pm 0.098$ & 0.91 \\
\hline \multicolumn{5}{|l|}{ 1-y $\Delta$ Weight, kg } \\
\hline $1-\mathrm{y} \Delta$ protein $\mathrm{CV}$ & $13.768 \pm 6.645$ & 0.059 & $-4.309 \pm 3.656$ & 0.27 \\
\hline $12 \mathrm{~m}$ Protein intake, $\mathrm{g} / \mathrm{d}$ & $-0.060 \pm 0.112$ & 0.60 & $0.033 \pm 0.098$ & 0.74 \\
\hline $12 \mathrm{~m}$ Total energy intake, $\mathrm{kcal}$ & $0.005 \pm 0.005$ & 0.37 & $0.002 \pm 0.002$ & 0.49 \\
\hline BL weight, $\mathrm{kg}$ & $-0.030 \pm 0.142$ & 0.84 & $0.052 \pm 0.165$ & 0.76 \\
\hline \multicolumn{5}{|l|}{ 1-y $\Delta$ Subcutaneous abdominal fat, $\mathbf{c m}^{2}$} \\
\hline $1-\mathrm{y} \Delta$ protein $\mathrm{CV}$ & $161.38 \pm 72.562$ & 0.046 & $30.984 \pm 82.927$ & 0.72 \\
\hline $12 \mathrm{~m}$ Protein intake, $\mathrm{g} / \mathrm{d}$ & $-0.999 \pm 1.258$ & 0.44 & $-1.330 \pm 2.828$ & 0.65 \\
\hline $12 \mathrm{~m}$ Total energy intake, $\mathrm{kcal}$ & $0.104 \pm 0.055$ & 0.08 & $0.004 \pm 0.049$ & 0.93 \\
\hline BL Subcutaneous abdominal fat, $\mathrm{cm}^{2}$ & $-0.213 \pm 0.168$ & 0.23 & $0.416 \pm 0.228$ & 0.11 \\
\hline \multicolumn{5}{|l|}{ 1-y $\Delta$ Quadriceps Muscle CSA, $\mathrm{cm}^{2}$} \\
\hline $1-\mathrm{y} \Delta$ protein $\mathrm{CV}$ & $7.757 \pm 3.884$ & 0.071 & $-7.822 \pm 8.073$ & 0.37 \\
\hline $12 \mathrm{~m}$ Protein intake, $\mathrm{g} / \mathrm{d}$ & $0.007 \pm 0.072$ & 0.92 & $0.040 \pm 0.180$ & 0.83 \\
\hline $12 \mathrm{~m}$ Total energy intake, $\mathrm{kcal}$ & $0.004 \pm 0.003$ & 0.23 & $0.000 \pm 0.005$ & 0.99 \\
\hline BL Quadriceps Muscle CSA, $\mathrm{cm}^{2}$ & $-0.031 \pm 0.083$ & 0.72 & $0.047 \pm 0.196$ & 0.82 \\
\hline
\end{tabular}

General linear model (Univariate ANOVA)

BL, baseline; CSA, cross-sectional area; CV, coefficient of variation; PA, physical activity; SA, successful aging; WL, weight loss; BMI, Body Mass Index. 


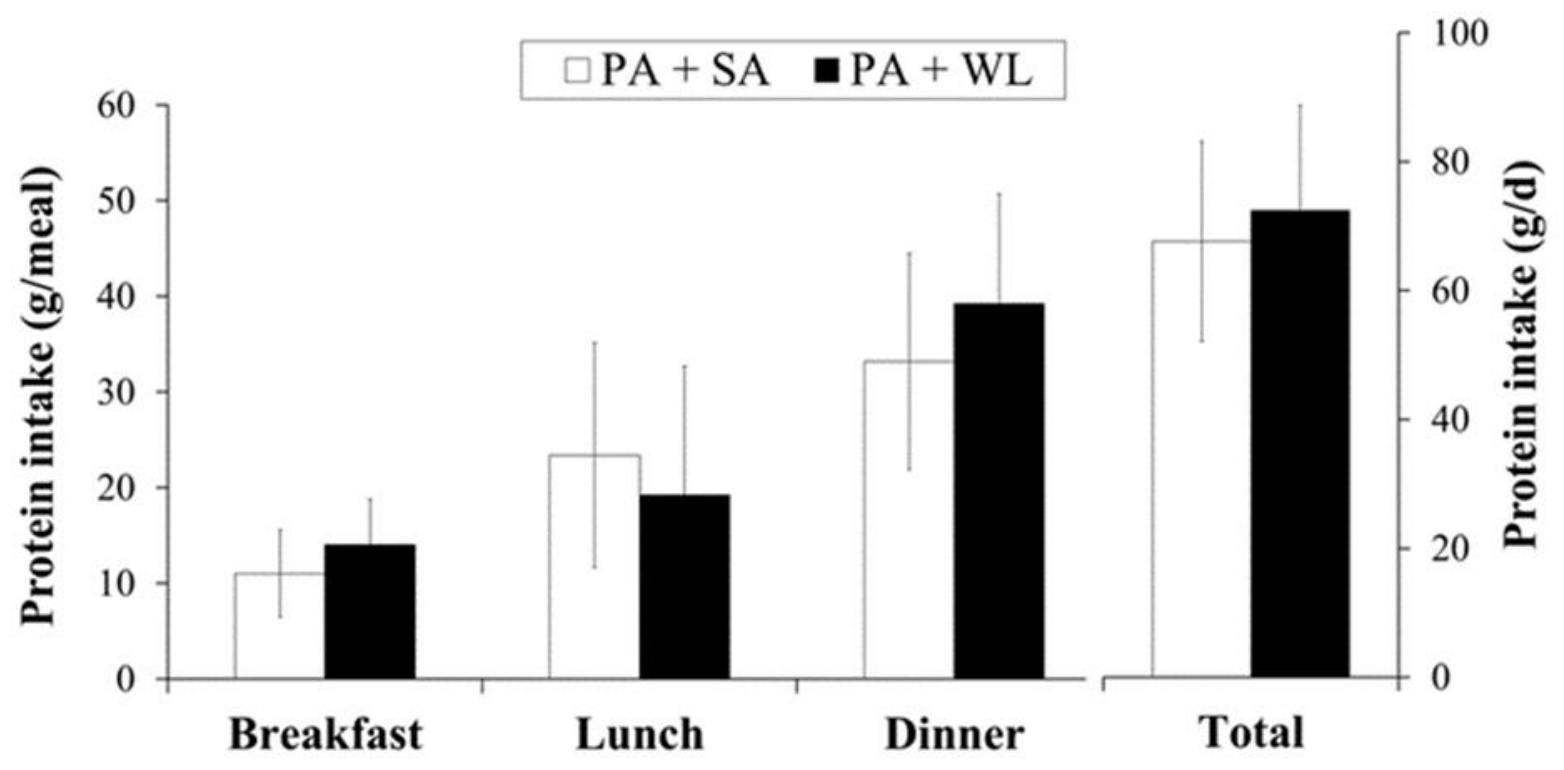

Figure 1. Mean \pm SD of baseline protein intake per meal and per day by intervention program

PA, physical activity; SA, successful aging health education; WL, weight loss 


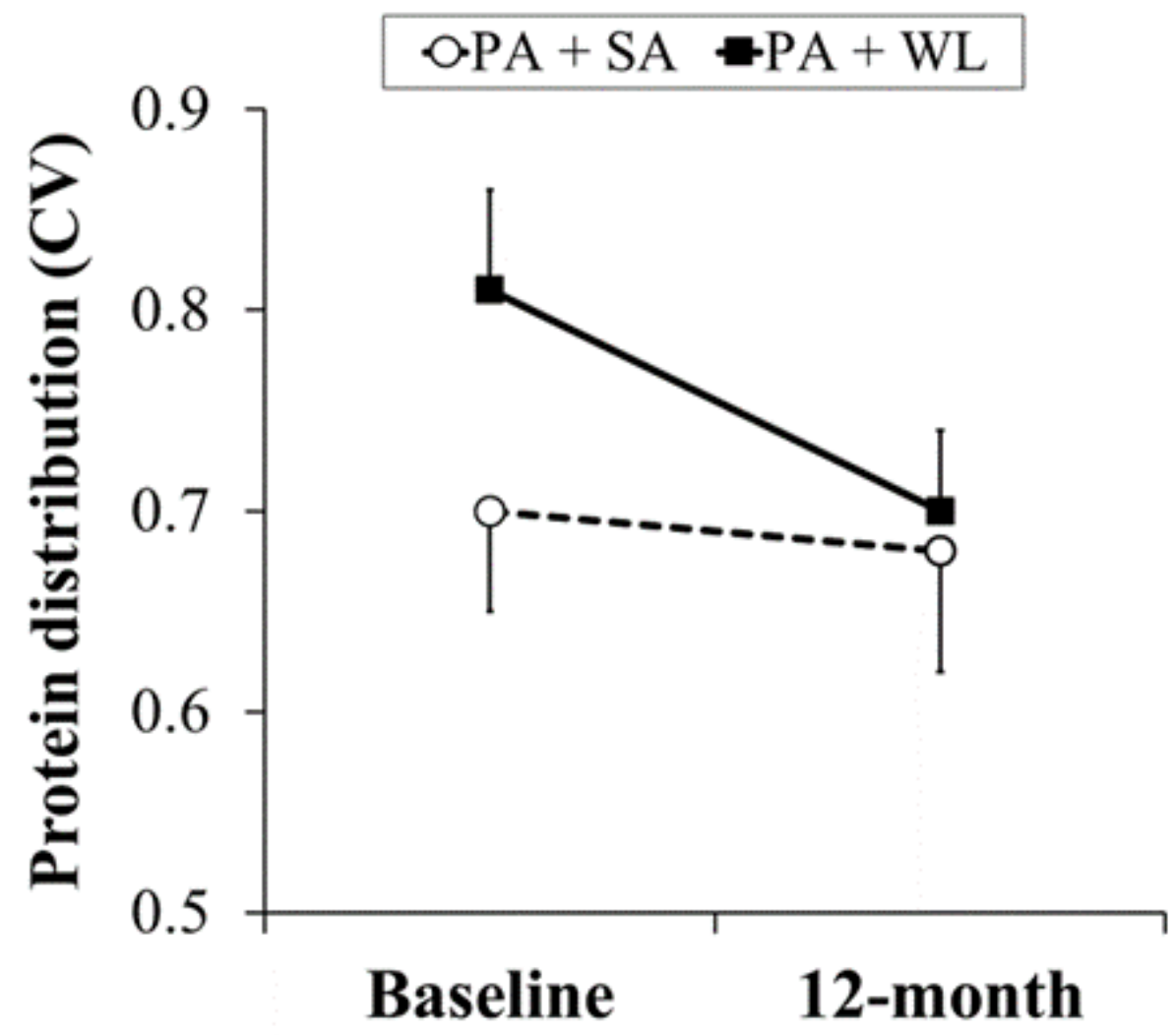

Figure 2. Mean $\pm \mathrm{SE}$ of baseline and 1-y change of protein intake distribution $\mathrm{CV}$, coefficient of variation, PA, physical activity; SA, successful aging; WL, weight loss $P$ obtained by paired sample t-test 


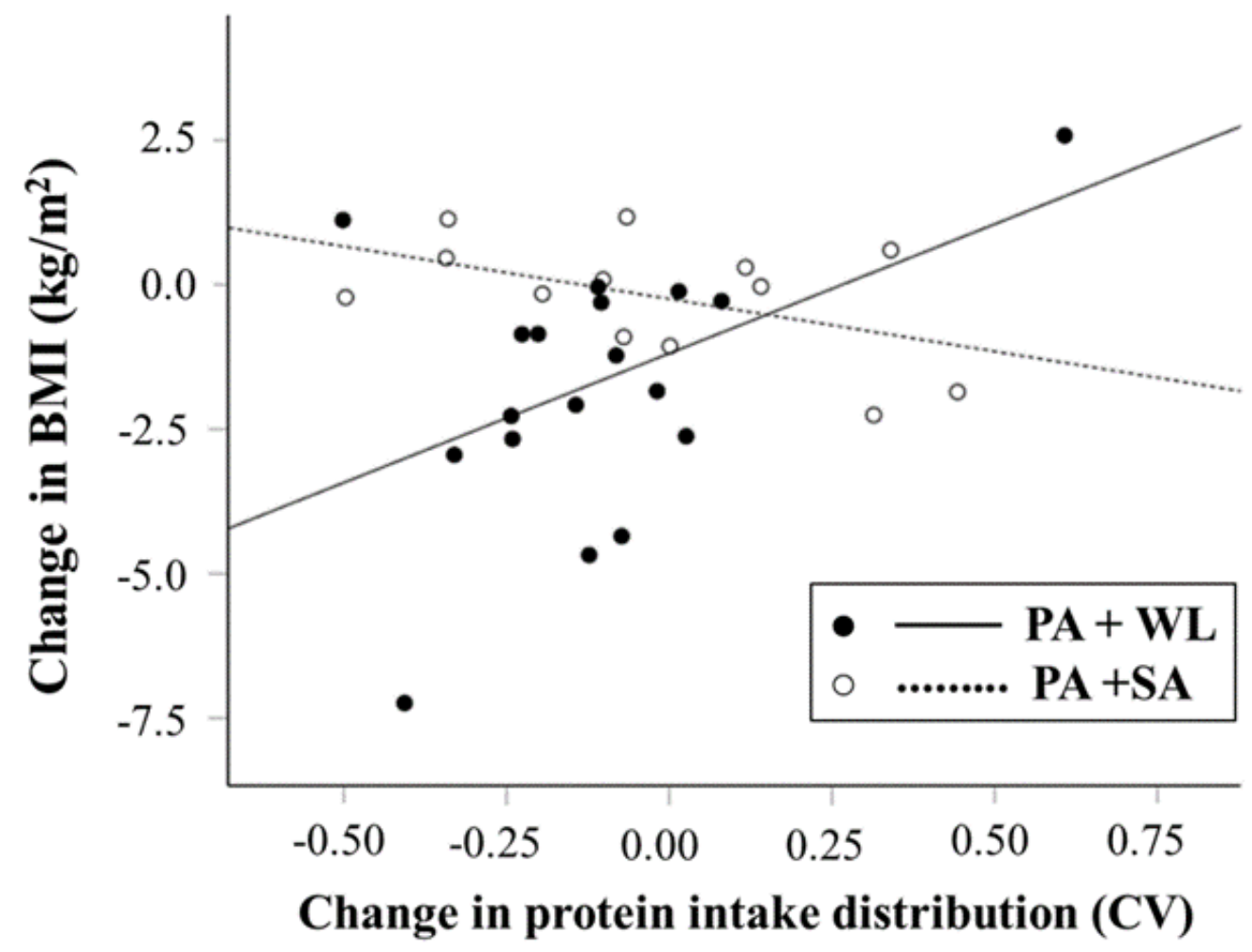

Figure 3. Relationship between 1-y changes in protein intake distribution and BMI by intervention program

PA, physical activity; SA, successful aging education program; WL, weight loss; BMI, Body Mass Index. 


\section{BIBLIOGRAPHY}

1. $\quad$ Fakhouri, T.H., et al., Prevalence of obesity among older adults in the United States, 20072010. NCHS Data Brief, 2012(106): p. 1-8.

2. Ogden, C.L., et al., Prevalence of childhood and adult obesity in the United States, 2011 2012. Jama, 2014. 311(8): p. 806-14.

3. Newman, A.B., Obesity in Older Adults. OJIN: The Online Journal of Issues in Nursing, 2009. 14(1).

4. Decaria, J.E., C. Sharp, and R.J. Petrella, Scoping review report: obesity in older adults. Int J Obes (Lond), 2012. 36(9): p. 1141-50.

5. Goodpaster, B.H., et al., Attenuation of skeletal muscle and strength in the elderly: The Health ABC Study. J Appl Physiol (1985), 2001. 90(6): p. 2157-65.

6. Therkelsen, K.E., et al., Intramuscular fat and physical performance at the Framingham Heart Study. Age (Dordr), 2016. 38(2): p. 31.

7. Hicks, G.E., et al., Absolute strength and loss of strength as predictors of mobility decline in older adults: the InCHIANTI study. J Gerontol A Biol Sci Med Sci, 2012. 67(1): p. 6673.

8. Lang, T., et al., Computed tomographic measurements of thigh muscle cross-sectional area and attenuation coefficient predict hip fracture: the health, aging, and body composition study. J Bone Miner Res, 2010. 25(3): p. 513-9.

9. Moreland, J.D., et al., Muscle weakness and falls in older adults: a systematic review and meta-analysis. J Am Geriatr Soc, 2004. 52(7): p. 1121-9.

10. Bosy-Westphal, A., et al., Contribution of individual organ mass loss to weight lossassociated decline in resting energy expenditure. Am J Clin Nutr, 2009. 90(4): p. 9931001.

11. Cava, E., N.C. Yeat, and B. Mittendorfer, Preserving Healthy Muscle during Weight Loss. Adv Nutr, 2017. 8(3): p. 511-519.

12. Weiss, E.P., et al., Lower extremity muscle size and strength and aerobic capacity decrease with caloric restriction but not with exercise-induced weight loss. J Appl Physiol (1985), 2007. 102(2): p. 634-40. 
13. Ross, R., et al., Reduction in obesity and related comorbid conditions after diet-induced weight loss or exercise-induced weight loss in men. A randomized, controlled trial. Ann Intern Med, 2000. 133(2): p. 92-103.

14. Janssen, I., et al., Effects of an energy-restrictive diet with or without exercise on abdominal fat, intermuscular fat, and metabolic risk factors in obese women. Diabetes Care, 2002. 25(3): p. 431-8.

15. Murphy, C.H., et al., Hypoenergetic diet-induced reductions in myofibrillar protein synthesis are restored with resistance training and balanced daily protein ingestion in older men. Am J Physiol Endocrinol Metab, 2015. 308(9): p. E734-43.

16. Areta, J.L., et al., Reduced resting skeletal muscle protein synthesis is rescued by resistance exercise and protein ingestion following short-term energy deficit. Am J Physiol Endocrinol Metab, 2014. 306(8): p. E989-97.

17. Leidy, H.J., et al., The role of protein in weight loss and maintenance. Am J Clin Nutr, 2015. 101(6): p. 1320s-1329s.

18. Thomas, D.T., K.A. Erdman, and L.M. Burke, American College of Sports Medicine Joint Position Statement. Nutrition and Athletic Performance. Medicine and science in sports and exercise, 2016. 48(3): p. 543-568.

19. Rand, W.M., P.L. Pellett, and V.R. Young, Meta-analysis of nitrogen balance studies for estimating protein requirements in healthy adults. Am J Clin Nutr, 2003. 77(1): p. 109-27.

20. Trumbo, P., et al., Dietary reference intakes for energy, carbohydrate, fiber, fat, fatty acids, cholesterol, protein and amino acids. J Am Diet Assoc, 2002. 102(11): p. 1621-30.

21. Farsijani, S., et al., Relation between mealtime distribution of protein intake and lean mass loss in free-living older adults of the NuAge study. Am J Clin Nutr, 2016. 104(3): p. 694703.

22. Farsijani, S., et al., Even mealtime distribution of protein intake is associated with greater muscle strength, but not with 3-y physical function decline, in free-living older adults: the Quebec longitudinal study on Nutrition as a Determinant of Successful Aging (NuAge study). Am J Clin Nutr, 2017. 106(1): p. 113-124.

23. Krok-Schoen, J.L., et al., Low Dietary Protein Intakes and Associated Dietary Patterns and Functional Limitations in an Aging Population: A NHANES analysis. J Nutr Health Aging, 2019. 23(4): p. 338-347.

24. Hickson, M., Nutritional interventions in sarcopenia: a critical review. Proc Nutr Soc, 2015. 74(4): p. 378-86. 
25. Houston, D.K., et al., Dietary protein intake is associated with lean mass change in older, community-dwelling adults: the Health, Aging, and Body Composition (Health ABC) Study. Am J Clin Nutr, 2008. 87(1): p. 150-5.

26. Bauer, J., et al., Evidence-based recommendations for optimal dietary protein intake in older people: a position paper from the PROT-AGE Study Group. J Am Med Dir Assoc, 2013. 14(8): p. 542-59.

27. Leidy, H.J., et al., Higher protein intake preserves lean mass and satiety with weight loss in pre-obese and obese women. Obesity (Silver Spring), 2007. 15(2): p. 421-9.

28. Evans, E.M., et al., Effects of protein intake and gender on body composition changes: $a$ randomized clinical weight loss trial. Nutr Metab (Lond), 2012. 9(1): p. 55.

29. Mamerow, M.M., et al., Dietary protein distribution positively influences $24-h$ muscle protein synthesis in healthy adults. J Nutr, 2014. 144(6): p. 876-80.

30. Hudson, J.L., et al., Within-day protein distribution does not influence body composition responses during weight loss in resistance-training adults who are overweight. Am J Clin Nutr, 2017. 106(5): p. 1190-1196.

31. US Department of Agriculture, A.R.S., Beltsville Human Nutrition Research Center, Food Surveys Research Group, and US Department of Health and Human Services, Centers for Disease Control and Prevention. What We Eat in America, NHANES 2009-2010 Data. 2009-2010 Feb 2019]; Available from: https://www.ars.usda.gov/SP2UserFiles/Place/80400530/pdf/0910/Table_1_NIN_GEN_0 9.pdf.

32. Gryson, C., et al., "Fast proteins" with a unique essential amino acid content as an optimal nutrition in the elderly: growing evidence. Clin Nutr, 2014. 33(4): p. 642-8.

33. Paddon-Jones, D., et al., Amino acid ingestion improves muscle protein synthesis in the young and elderly. Am J Physiol Endocrinol Metab, 2004. 286(3): p. E321-8.

34. Katsanos, C.S., et al., Aging is associated with diminished accretion of muscle proteins after the ingestion of a small bolus of essential amino acids. Am J Clin Nutr, 2005. 82(5): p. 1065-73.

35. Dardevet, D., et al., Muscle wasting and resistance of muscle anabolism: the "anabolic threshold concept" for adapted nutritional strategies during sarcopenia. ScientificWorldJournal, 2012. 2012: p. 269531.

36. Hudson, J.L., R.E.B. Iii, and W.W. Campbell, Protein Distribution and Muscle-Related Outcomes: Does the Evidence Support the Concept? Nutrients, 2020. 12(5). 
37. Murphy, C.H., et al., Effect of resistance training and protein intake pattern on myofibrillar protein synthesis and proteome kinetics in older men in energy restriction. J Physiol, 2018. 596(11): p. 2091-2120.

38. Santanasto, A.J., et al., Impact of weight loss on physical function with changes in strength, muscle mass, and muscle fat infiltration in overweight to moderately obese older adults: a randomized clinical trial. J Obes, 2011.

39. Santanasto, A.J., et al., Body Composition Remodeling and Mortality: The Health Aging and Body Composition Study. The Journals of Gerontology: Series A, 2017. 72(4): p. 513519.

40. Diabetes Prevention Program Research, G., The Diabetes Prevention Program (DPP): description of lifestyle intervention. Diabetes care, 2002. 25(12): p. 2165-2171.

41. Sipila, S., et al., Effects of strength and endurance training on isometric muscle strength and walking speed in elderly women. Acta Physiol Scand, 1996. 156(4): p. 457-64.

42. Fielding, R.A., et al., Activity adherence and physical function in older adults with functional limitations. Med Sci Sports Exerc, 2007. 39(11): p. 1997-2004.

43. Stewart, A.L., et al., CHAMPS physical activity questionnaire for older adults: outcomes for interventions. Med Sci Sports Exerc, 2001. 33(7): p. 1126-41.

44. Visser, M., et al., Validity of fan-beam dual-energy X-ray absorptiometry for measuring fat-free mass and leg muscle mass. Health, Aging, and Body Composition Study--DualEnergy X-ray Absorptiometry and Body Composition Working Group. J Appl Physiol (1985), 1999. 87(4): p. 1513-20.

45. Goodpaster, B.H., et al., Association between regional adipose tissue distribution and both type 2 diabetes and impaired glucose tolerance in elderly men and women. Diabetes Care, 2003. 26(2): p. 372-9.

46. Goodpaster, B.H., et al., Effects of physical activity on strength and skeletal muscle fat infiltration in older adults: a randomized controlled trial. J Appl Physiol (1985), 2008. 105(5): p. 1498-503.

47. Loenneke, J.P., et al., Per meal dose and frequency of protein consumption is associated with lean mass and muscle performance. Clin Nutr, 2016. 35(6): p. 1506-1511.

48. Mitchell, C.J., et al., What is the relationship between the acute muscle protein synthesis response and changes in muscle mass? J Appl Physiol (1985), 2015. 118(4): p. 495-7.

49. Paddon-Jones, D., et al., Protein, weight management, and satiety. Am J Clin Nutr, 2008. 87(5): p. 1558s-1561s. 
50. McHill, A.W., et al., Later circadian timing of food intake is associated with increased body fat. The American journal of clinical nutrition, 2017. 106(5): p. 1213-1219. 